AUTHOR(S):

SUBMITTED TO:
Joseph E. Nasise

Charles $\mathrm{R}$. Walthers

Richard W. Basinger 


\section{DISCLAIMER}

Portions of this document may be illegible in electronic image products. Images are produced from the best available original document. 


\title{
A SELF-ASSAYING TRITIUM STORAGE BED FOR ITER
}

\author{
J. E. Nasise, C. R. Walthers and R. W. Basinger \\ Los Alamos National Laboratory \\ P.O. Box 1663, MS C348 \\ Los Alamos, New Mexico 87545
}

(505) 667-1459

\begin{abstract}
A safe metal-hydride "self-assaying" tritium storage bed, featuring accurate tritium assaying measurements is being designed, built, and tested at the Tritium Systems Test Assembly (TSTA) at the Los Alamos National Laboratory (LANL) for the International Thermonuclear Experimental Reactor (ITER) program. Time consuming inventory operations can be shortened by utilizing "selfassaying" tritium storage beds. Design considerations, calculations, problems, and construction details of the bed are presented. Sensitivity, predictability, and simplicity are optimized in this design by utilizing thermal radiation as the primary mode of heat transfer. Thermal analysis calculations have shown that the design may provide 15 times the ITER required sensitivity at full capacity of $150 \mathrm{gT}$.
\end{abstract}

\section{INTRODUCTION}

Today's large tritium handling facilities are still dependent on pressure-volume-temperature and gas composition (PVTC) for accurate tritium accountancy measurements. Typically, regulatory authorities require tritium handling facilities to perform accountancy measurements every six months; this may require a complete plant shutdown and can take up to a week or more to perform. These time consuming inventory operations can be shortened by utilizing "self-assaying" tritium storage beds. These types of storage beds, commonly called "self-assaying," were first proposed for ITER by TSTA in a Conceptual Design Description for ITER in 1990 and in a Fusion Technology paper in $1991{ }^{1}$ This convenient and accurate method of tritium accountancy is currently being used at TSTA for portable tritium transfers, for up to six grams of tritium, and is currently planned for ITER if acceptable performance can be achieved with large capacity beds. Goals set by the ITER Tritium Plant Group for these large-capacity self-assaying beds are: 1) the bed should be designed based on depleted uranium as a storage material; 2) total capacity should be 200 grams of tritium at full stoichiometric loading with an operating capacity of 150 grams; and 3) tritium measurement accuracy should be better than $1 \%$ at 150 grams.

\section{DESIGN}

The proposed bed design is based on the current TSTA Self-Assaying Portable Uranium Bed (SAPUB) that operates on the principal that decayheat of stored tritium in a thermally insulated container will cause a measurable and repeatable temperature rise. ${ }^{2}$ Vacuum is used to thermally insulate the uranium primary container from the environment.

The primary design objective is to achieve the necessary thermal resistance to allow the uranium primary container at $150 \mathrm{gT}$, full tritium loading, to self-heat to $\sim 300^{\circ} \mathrm{C}$ while maintaining the secondary container temperature at $\sim 40{ }^{\circ} \mathrm{C}$. A uraniumhydride tritium storage bed is typically dehydrided at temperatures between 450 and $500{ }^{\circ} \mathrm{C}$; therefore, a temperature of $\sim 300{ }^{\circ} \mathrm{C}$ was selected. Design analysis required the solution of fourth-order radiation heat transfer equations which was accomplished by computer. Many bed configurations were considered prior to the final bed selection. Two layers of Kapton/Aluminum insulation, to thermally insulate the primary uranium container, was considered. This configuration met the design objectives by allowing the primary container to reach $\sim 300 \quad{ }^{\circ} \mathrm{C}$, under vacuum conditions at full loading, while the secondary container temperature remained at $\sim 40{ }^{\circ} \mathrm{C}$. However, selection of the radiative surface properties must be carefully considered to minimize bed-to-bed 
performance variations for tritium storage systems utilizing multiple beds. Since low and stable emittance values are significant factors that govern the accuracy and repeatability of this design, nonprotected stainless steel surfaces were found less favorable because of probable changes in the emittance of stainless steel due to oxidation. Radiative surface properties should remain stable after thermal-cycling and over time; therefore, gold was a reasonable choice to satisfy these surface property requirements.

Based on the ITER requirements of a stochiometric loading of $200 \mathrm{gT}\left(33.16 \mathrm{~mol} \mathrm{~T}_{2}\right.$ ) and using the following equation, a total of $5.26 \mathrm{Kg}$ $(22.1 \mathrm{~mol} \mathrm{U})$ of depleted uranium is required.

$$
\mathrm{U}+1.5 \mathrm{~T}_{2} \rightarrow \mathrm{UT}_{3}
$$

Assuming a conservative uranium-hydride density of $2.6 \mathrm{~g} / \mathrm{cc}$, the resulting uranium primary container volume required is 2.09 liters. A cylindrical vessel with an internal diameter of 12.7 $\mathrm{cm}$ and an internal length of $16.51 \mathrm{~cm}$ was selected to contain this volume.

The following mathematical thermal analysis modeling is based on gold-plated interior surfaces. Design calculations are based on the model shown in Figure 1. A uranium-filled primary container is suspended from a top lid surrounded by a $35.56 \mathrm{~cm}$ diameter by $34.29 \mathrm{~cm}$ long secondary containment vessel, that also serves as a vacuum jacket.

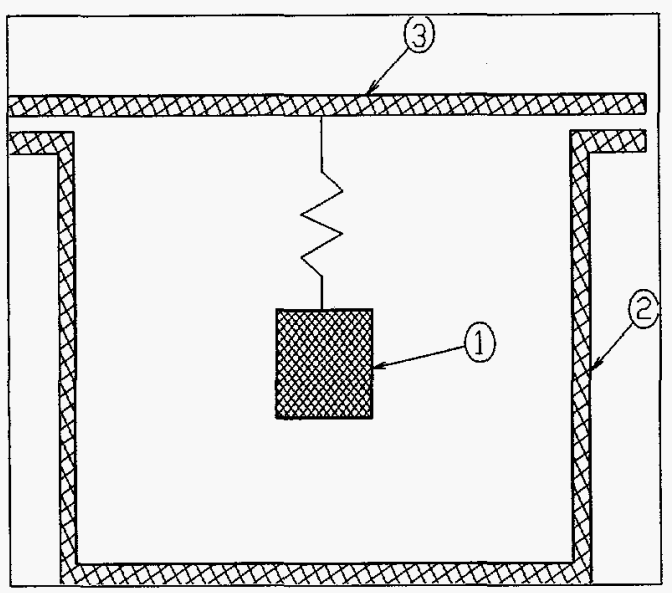

Figure 1. Model used for design analysis calculations.
The equations used in the analysis are listed below:

$$
\begin{aligned}
& \mathrm{Q}_{1-2}=\left(F \varepsilon A-F \varepsilon A_{\text {wire }}\right) \sigma\left(T_{1}{ }^{4}-T_{2}{ }^{4}\right) \\
& Q_{2-a m b}=h_{2} A\left(T_{2}-T_{\text {amb }}\right) \\
& Q_{1-3}=F \varepsilon A \sigma\left(T_{1}-T_{3}{ }^{4}\right)+U\left(T_{1}-T_{3}\right) \\
& Q_{3-a m b}=h_{3} A\left(T_{3}-T_{\text {amb }}\right)
\end{aligned}
$$

where, $Q$ is the rate of heat transfer; $F$ the shape factor or percentage of radiation leaving the primary container and impinging on the surrounding surfaces; $\varepsilon$ the effective emissivity, including the effects of multiple reflections; $A$ the surface area; $\sigma$ the Stefan-Boltzman constant; $h$ the convective film coefficient; $U$ the over-all conduction coefficient; and $\mathrm{T}$ the absolute temperature. Corrections for the convective film coefficient as a function of temperature, and corrections for the conduction and radiation losses from the primary container's mechanical supports and electrical connections are accounted for in the equations.

By assuming a lid temperature $T_{3}$, and a constant ambient temperature $T_{\text {amb }}$ and balancing equations 6 , 7 , and 8 , the power or grams of tritium and the temperatures $T_{1}$ and $T_{2}$ can be determined.

$$
\begin{aligned}
& \mathrm{Q}_{1-3}=\mathrm{Q}_{3-\mathrm{amb}} \\
& \mathrm{Q}_{1-2}=\mathrm{Q}_{2-\mathrm{amb}} \\
& \mathrm{Q}_{\text {total }}=\mathrm{Q}_{2-\mathrm{amb}}+\mathrm{Q}_{\text {3-amb }}
\end{aligned}
$$

Solution of these heat balances showed that the necessity for radiation shields could be eliminated if the surface emittance value could be lowered to $\sim 0.04$. These low values are obtainable by gold plating. Table 1 shows the data from these iterative calculations based on an emissivity value of 0.04 . Listed are the tritium loading in grams, sensitivity in curies, and the three surface temperatures.

To provide accurate temperature measurements Platinum Resistance Temperature Devices (RTDs) are used. These devices are accurate to better than $0.1{ }^{\circ} \mathrm{C}$. Performance changes due to possible localized hydriding during times of low tritium loading is also a concern. To measure any possible temperature variations 12 RTDs are provided on the surface of the primary container, six around the circumference and three each at the top and bottom.

As in the SAPUB design, the RTD temperature sensors are potted into metal plates and mechanically fastened to the primary container. The temperature 
error across these plates was calculated, assuming a temperature of $450^{\circ} \mathrm{C}$ and a $10 \%$ contact area, and found to be only $0.001{ }^{\circ} \mathrm{C}$.

Bed sensitivity values, in curies, are calculated from the following equation:

$$
\text { Sensitivity }(\mathrm{Ci})=953.6 \mathrm{dg}_{\text {tritium }} / \mathrm{dT}
$$

where, the constant 953.6 results from converting grams of tritium to curies and multiplying by the RTD accuracy factor of $0.1 ; \mathrm{dg}_{\text {tritium }} / \mathrm{dT}$ is the tritium loading difference available from the results described above. This coupled with the RTD accuracy of $0.1{ }^{\circ} \mathrm{C}$ results in a determination that the measurement sensitivity is $944 \mathrm{Ci}$ at $157 \mathrm{gT}$ which is $\sim 15$ times the ITER requirement. Figure 2 shows the primary container temperature $\left(T_{1}\right)$ verses tritium loading in grams while Figure 3 shows the sensitivity in curies verses tritium loading in grams.

Table 1. Bed loading in gT; bed sensitivity in curies; primary container temperature $T_{1}$; secondary containment temperature $\mathrm{T}_{2}$; and the top lid temperature $T_{3}$.

\begin{tabular}{|c|c|c|c|c|}
\hline gT 2 & Sen.(Ci) & T 1, (C) & T2, (C) & T3, (C) \\
\hline 0.00 & 212 & 21.11 & 21.11 & 21.11 \\
\hline 0.22 & 221 & 22.10 & 21.18 & 21.29 \\
\hline 1.25 & 232 & 26.54 & 21.38 & 21.85 \\
\hline 2.55 & 242 & 31.88 & 21.57 & 22.41 \\
\hline 5.64 & 258 & 44.04 & 22.01 & 23.52 \\
\hline 9.29 & 276 & 57.52 & 22.48 & 24.63 \\
\hline 13.46 & 296 & 71.93 & 23.01 & 25.74 \\
\hline 18.15 & 318 & 87.06 & 23.58 & 26.85 \\
\hline 23.38 & 343 & 102.72 & 24.21 & 27.96 \\
\hline 29.18 & 371 & 118.83 & 24.89 & 29.07 \\
\hline 35.58 & 401 & 135.29 & 25.72 & 30.18 \\
\hline 42.62 & 436 & 152.01 & 26.61 & 31.29 \\
\hline 50.35 & 472 & 168.93 & 27.47 & 32.41 \\
\hline 58.80 & 512 & 186.01 & 28.50 & 33.52 \\
\hline 68.01 & 554 & 203.17 & 29.61 & 34.63 \\
\hline 78.01 & 601 & 220.37 & 30.88 & 35.74 \\
\hline 88.85 & 650 & 237.58 & 32.17 & 36.85 \\
\hline 100.55 & 703 & 254.76 & 33.57 & 37.96 \\
\hline 113.16 & 758 & 271.88 & 35.04 & 39.07 \\
\hline 126.69 & 818 & 288.90 & 36.59 & 40.18 \\
\hline 141.18 & 879 & 305.80 & 38.21 & 41.29 \\
\hline 156.67 & 944 & 322.60 & 39.96 & 42.41 \\
\hline 173.09 & 1008 & 339.19 & 41.80 & 43.52 \\
\hline 190.45 & 1086 & 355.61 & 43.73 & 44.63 \\
\hline 208.93 & 1155 & 371.83 & 45.76 & 45.74 \\
\hline 228.29 & 1236 & 387.81 & 47.88 & 46.85 \\
\hline 248.77 & 1311 & 403.62 & 50.06 & 47.96 \\
\hline 270.19 & 1387 & 419.20 & 52.27 & 49.07 \\
\hline 292.52 & 1477 & 434.56 & 54.86 & 50.18 \\
\hline 316.02 & 1562 & 449.73 & 57.06 & 51.29 \\
\hline 340.41 & & 464.62 & 59.59 & 52.41 \\
\hline
\end{tabular}

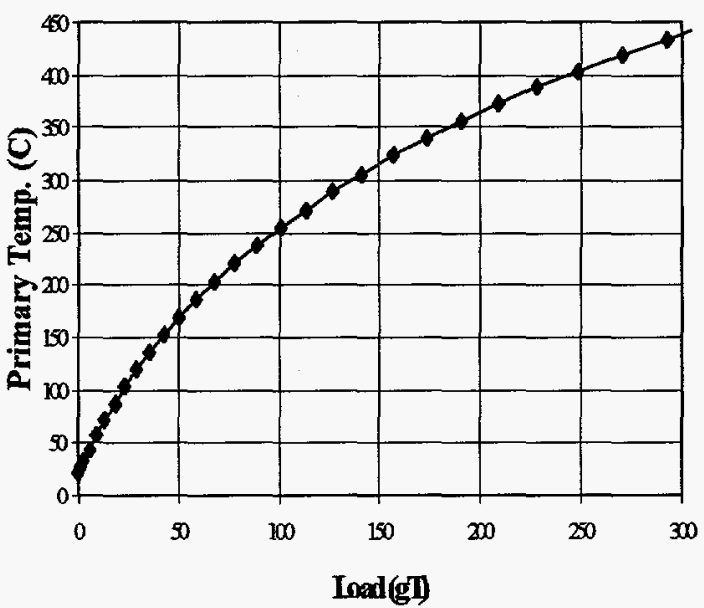

Figure 2. Primary uranium container temperature $T_{\mathfrak{l}}$ verses the tritium loading in grams.

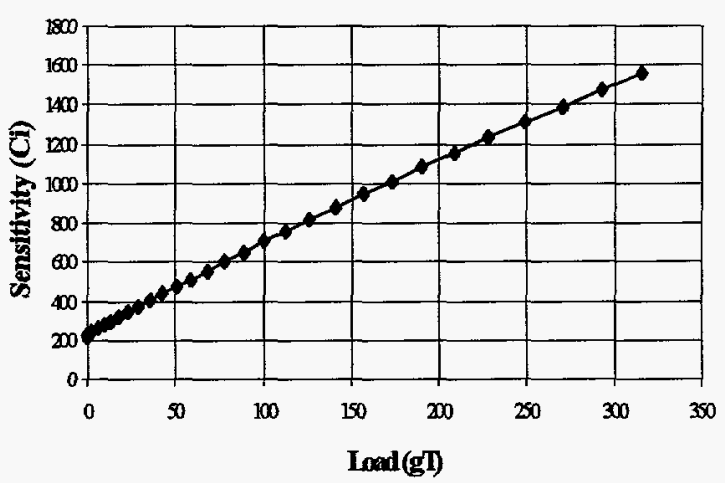

Figure 3. Primary uranium container measurement sensitivity in curies verses tritium loading in grams.

\section{DESIGN FEASIBILITY STUDIES}

Gold plating is selected in this design based on the theoretical benefits of this material to satisfy the stringent requirements necessary for an uncomplicated, sensitive, and predictable selfassaying bed for ITER. However, prior to bed fabrication; emissivity changes; diffusion rate; surface preparation and gold plating thickness are all concerns and must be addressed. To minimize the plating variables for this bed, type 316 stainless steel was selected for the construction material. Also, the stainless steel vacuum surfaces will be plated with nickel to provide a diffusion barrier between the stainless steel and the gold. Nickel is commonly 
used to enhance the adhesion of gold to stainless steel and to improve plating quality.

A series of tests using type 316 stainless steel samples were performed to examine the viability of the subject gold plating at the conditions expected for the self-assaying bed. The first test showed that target emissivity values below 0.04 could be obtained. Two samples were prepared, one electropolished and the other mechanically polished. The results showed that both samples produced acceptable emissivity values of 0.027 and 0.013 respectively, but the mechanically polished sample gave the lower emissivity value. Two additional mechanically polished samples were prepared to check plating thickness control. One sample was plated with $13 \mu \mathrm{m}$ of gold and the other plated with $25 \mu \mathrm{m}$ of gold.

Diffusion studies were performed on the above samples by placing them in a vacuum oven at $450{ }^{\circ} \mathrm{C}$. After 21 days at $450{ }^{\circ} \mathrm{C}$ the samples were removed from the oven and examined with a Scanning Electron Microscope (SEM). Metallography results of the samples showed a discrete interface between the gold and the stainless steel substrate indicating that no significant diffusion of gold had occurred The nickel under plate could not be seen due to the fact that the Z-numbers for nickel and the constituents of stainless steel are almost the same. Also, no measurable thickness changes were observed from the samples.

While these initial test results are encouraging they are not conclusive due to poor experimental control. For example, it was discovered that the sample heating oven lost vacuum at temperature, for an unknown amount of time, and therefore badly discolored the gold and oxidized the stainless steel. It is assumed that the discoloration was caused by vacuum pump oil back-streaming and oxidizing on the samples. Emissivity values taken that day confirmed the badly discolored gold surfaces. Also, only a nickel "strike" was used on the samples of an unknown thickness.

Since the performance characteristics of this bed relies heavily on these results an oven dedicated solely to these tests was obtained and will be used for future sample studies. Also, improvements in the gold plating process are being made. It was learned that a sulfide bath contains leveling agents that produce a much smoother gold surface. The sulfide gold bath may provide lower emissivity values than the cyanide bath that was used in the earlier samples. Therefore, five more samples were prepared and all plated with $6 \mu \mathrm{m}$ of nickel. Three samples, 3B.0005 , 3B-.001, and 3B-.002, were gold plated using the sulfide bath to gold thickness of $13 \mu \mathrm{m}, 25 \mu \mathrm{m}$, and $51 \mu \mathrm{m}$, respectively. The remaining two samples, 3-316-.001 and 3-316-.002, were plated using the cyanide bath to gold thickness of $25 \mu \mathrm{m}$ and $51 \mu \mathrm{m}$, respectively. Initial emissivity values of the three sulfide bath samples as plated all measured 0.017 while the two samples prepared with the cyanide bath both measured 0.015 as plated. This shows that consistent emissivity values can be obtained and the cyanide bath is better over the entire spectral range. Visibly the sulfide samples appear brighter. The lower section of the sulfide samples were lightly polished to see if the emissivity could be improved, this resulted in higher emissivity values of 0.018 . A summary of the initial emissivity values are listed in Table 2.

Table 2. Sample emissivity results.

\begin{tabular}{|c|c|}
\hline Sample Number & Initial Emissivity \\
\hline 3B-.0005 & 0.018 \\
\hline 3B-.001 & 0.018 \\
\hline 3B-.002 & 0.018 \\
\hline 3-316-.001 & 0.015 \\
\hline $3-316-.002$ & 0.015 \\
\hline
\end{tabular}

\section{BED CONSTRUCTION}

External construction of this bed is very similar to the five tritium storage beds which have been in service at TSTA for 11 years; however, the internal components are quite different. Like the TSTA bed, secondary containment is provided by a $53.3 \mathrm{~cm} 68$ $\mathrm{kg}$ (21 inch 150\#) flange that serves as the top for a $35.56 \mathrm{~cm}$ diameter by $34.29 \mathrm{~cm}$ long secondary containment vessel that also serves as a vacuum jacket. A $14 \mathrm{~cm}$ diameter by $21.6 \mathrm{~cm}$ long primary container is suspended from the top flange by three $25.4 \mathrm{~mm}$ diameter support tubes welded to the bottom of the flange. The wall thickness of the support tubes are kept to a minimum and the length of the inlet and outlet tubes are made longer than necessary to minimize heat conduction.

The primary container comprises two end caps; a central section; two RTD end plates; six RTD side plates; two copper lattices; three $10 \mu \mathrm{m}$ stainless steel frit filters; and three 240 volt 1000 watt heaters. 
The $5.26 \mathrm{~kg}$ of depleted uranium is distributed uniformly in the two copper lattices, consisting of 21 compartments each, while the three $10 \mu \mathrm{m}$ stainless steel frit filters confine the uranium. End caps with internally machined circular gas plenums provide uniform gas distribution through the bed. Figure 4 shows the internal construction of the primary container including the heaters and RTD plates.
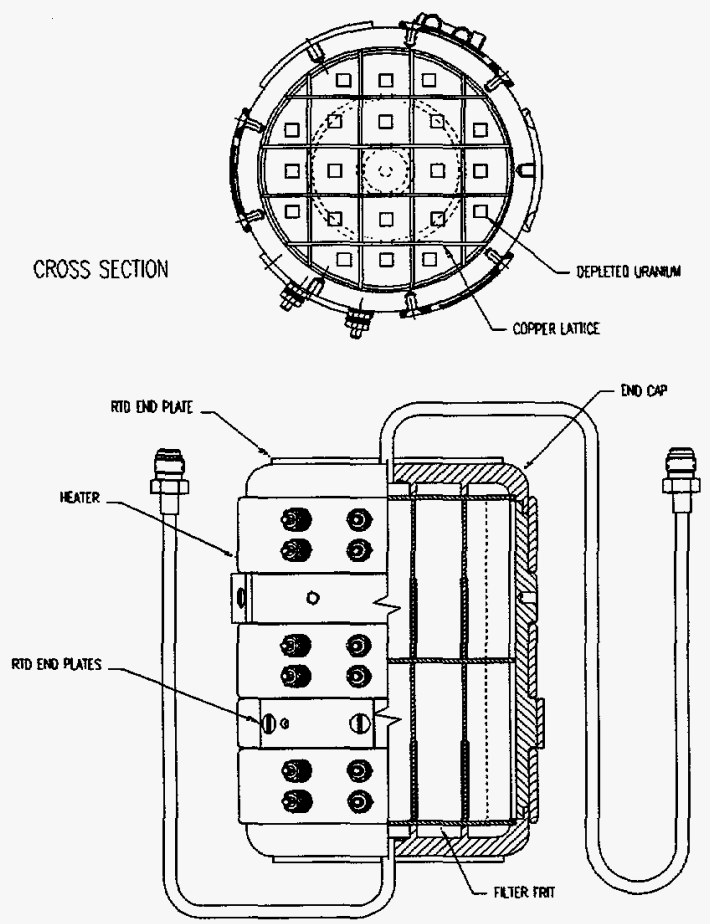

Figure 4. Primary container components.

Three stainless steel frit filters are sealed within the primary container by welding. The stack height of the internal primary components are $0.5 \mathrm{~mm}$ taller than the outer containment vessel, therefore, when the final end cap is welded to the primary container the shrinkage, resulting from the welding, forces the internal components together resulting in a tight filter seal. Good thermal conduction from the primary container to the RTD plates is provided by screws.

A complete set of mechanical drawings were produced for this design. Figure 5 is a drawing of the storage bed showing the major components.

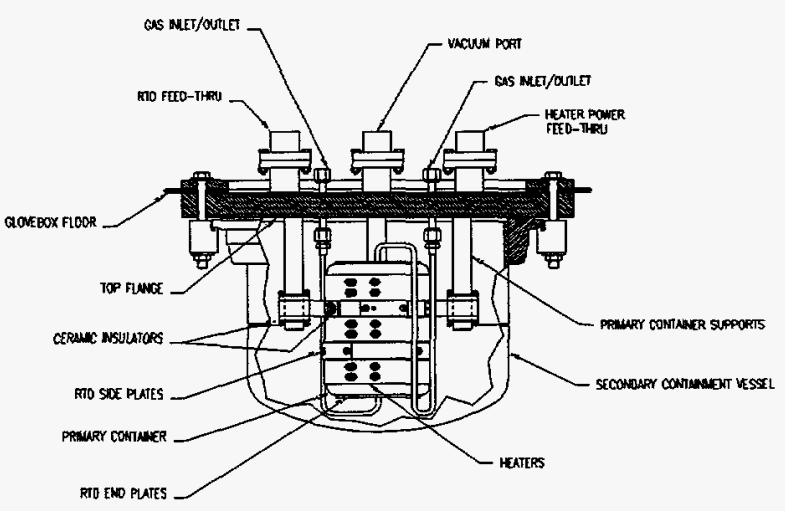

Figure 5. Bed assembly drawing.

\section{PLANNED TESTING}

A series of calibration runs will be performed to confirm the thermal characteristics of the bed. Accurate electrical heater power and temperature measurements will be compared to the predicted values. Recalling that the ambient temperature was a constant in the model calculations; the secondary containment vessel temperature will have to be held constant to achieve the calculated sensitivities.

Ultimate calibration and evaluation of the bed will be performed with tritium. Pre-measured amounts of tritium will be added to the bed and the bed allowed to come to thermal equilibrium. The equilibrium times and temperatures will be documented. These tests will be repeated over time to determine the long term behavior of the selfassaying bed.

It has been shown that this bed with come to thermal equilibrium in 13 hours once fully loaded. However, additional tests are planned to decrease this assay time at the expense of sensitivity. These tests will be done with the secondary containment vessel at atmospheric pressure. Tests planned include flow-through tests, tritium sensitivity measurements at atmospheric pressure, etc. An increase in primary container temperature proportional to tritium loading is observed with the current TSTA beds.

\section{v. CONCLUSIONS}

A self-assaying tritium storage bed with theoretical tritium measurement sensitivities to within 221 curies at $0.2 \mathrm{gT}$ loading and 944 curies at 
$156 \mathrm{gT}$ loading was designed for ITER. The design is based on radiative heat transfer using gold-plated vacuum surfaces. The advantages gained with goldplated vacuum surfaces are stable bed-to-bed performance and design simplicity. Also, gold has a low permeation rate for tritium. Based on goldplated sample tests low surface emissivity values can be obtained eliminating the need for radiation shields. Time consuming tritium inventory operations involving PVTC analysis may be eliminated by the use of these self-assaying tritium storage beds for large capacity tritium inventory facilities.

\section{ACKNOWLEDGMENTS}

This work is supported by the U.S. Department of Energy, Office of Fusion Energy.

\section{REFERENCES}

1. J. E. Nasise, M. E. Muller and J. L. Anderson, "ITER Fuel Storage System Conceptual Design Description," Fusion Technology, Vol. 19, 1657 (1991)

2. Charles R. Walthers and Everett M. Jenkins "The Tritium Systems Test Assembly Self-Assaying Portable Uranium Bed", $15^{\text {th }}$ IEEE/NPSS Fusion Engineering, Oct. 11- 15,1993, Hyannis, MA., pp. 56-60 